\title{
Surface finishing of hard-to-machine cladding alloys for highly stressed components
}

\author{
Dirk Schroepfer $^{1}$ (1) $\cdot$ Kai Treutler ${ }^{2} \cdot$ Andreas Boerner $^{1} \cdot$ Rene Gustus $^{3} \cdot$ Thomas Kannengiesser $^{1} \cdot$ Volker Wesling $^{2}$. \\ Wolfgang Maus-Friedrichs ${ }^{3}$
}

Received: 13 November 2020 / Accepted: 9 February 2021 / Published online: 29 March 2021

(C) The Author(s) 2021

\begin{abstract}
The supply and processing of materials for highly stressed components are usually cost-intensive. Efforts to achieve cost and resource efficiency lead to more complex structures and contours. Additive manufacturing steps for component repair and production offer significant economic advantages. Machining needs to be coordinated with additive manufacturing steps in a complementary way to produce functional surfaces suitable for the demands. Regarding inhomogeneity and anisotropy of the microstructure and properties as well as production-related stresses, a great deal of knowledge is still required for efficient use by small- and medium-size enterprises, especially for the interactions of subsequent machining of these difficult-to-machine materials. Therefore, investigations on these influences and interactions were carried out using a highly innovative cost-intensive NiCrMo alloy (IN725). These alloys are applied for claddings as well as for additive component manufacturing and repair welding using gas metal arc welding processes. For the welded specimens, the adequate solidification morphology, microstructure and property profile were investigated. The machinability in terms of finishing milling of the welded surfaces and comparative analyses for ultrasonic-assisted milling processes was examined focussing on surface integrity. It was shown that appropriate cutting parameters and superimposed oscillating of the milling tool in the direction of the tool rotation significantly reduce the mechanical loads for tool and workpiece surface. This contributes to ensure a high surface integrity, especially when cutting has to be carried out without cooling lubricants.
\end{abstract}

Keywords WAAM · IN725 · Machining - Ultrasonic-assisted milling · Residual stresses · Cutting forces · Surface integrity $\cdot$ Microstructure

\section{Introduction}

In order to meet the demands for reduced release of greenhouse gases, process emissions from the industry need to be considerably decreased through greater energy, resource and material efficiency. To achieve this goal, facility components that are exposed to corrosive and tribological stresses as well as high thermal and mechanical loads are particularly critical. Both the acquisition and

Dirk Schroepfer

dirk.schroepfer@bam.de

1 BAM Federal Institute for Materials Research and Testing, Unter den Eichen 87, 12205, Berlin, Germany

2 TU Clausthal, Institute of Welding and Machining, Agricolastraße 2, 38678, Clausthal-Zellerfeld, Germany

3 TU Clausthal, Clausthal Centre for Material Technology, Agricolastraße 2, 38678, Clausthal-Zellerfeld, Germany processing of materials for such combined stresses, such as nickel and cobalt-chromium alloys, are cost-intensive. Furthermore, today's efforts to achieve cost and resource efficiency increasingly lead to lightweight construction and thus to more complex structures and contours. In this context, the use of additive manufacturing (AM) steps to repair components, apply protective coatings or to form entire components is often associated with significant ecological advantages.

As described in [1], in some cases, additive manufacturing is the only way to achieve an economical component production. Examples can be found for components in tool, turbine or plant construction. In addition, most applications require particularly high dimensional accuracy and integrity of the component surfaces due to safety, cost and technological aspects. For the repair and manufacture of highly stressed, cost-intensive components, additive and machining manufacturing steps can be used in a complementary manner as it is discussed in [2]. The focus is particularly on 
cost-intensive materials for high-temperature applications such as NiCrMo alloys. Due to the very difficult-to-machine nature of these alloys, the combined additive and machining production has a particularly high economic potential for these applications. For this purpose, however, it is urgently necessary to coordinate the technologies in a targeted manner in order to generate the often-times complex final contours precisely on the one hand and to economically produce functional surfaces suitable for the demands on the other hand. For the economic use of such combined processes, important questions still need to be clarified. In particular, this concerns metallurgy, inhomogeneity and anisotropy of the special microstructure and properties in the generation of metals, which was for instance discussed in an overview work recently for powder bed fusion AM process by Malekipour and El-Mounayri [3]. Following the work of Nadammal et al. [4] especially in NiCrMo alloys, e. g. IN718, care should be taken regarding the AM processing parameters and build-up strategy, since these largely determine the residual stresses and microstructure in the produced components. In addition, the property changes and stresses in the boundary zones of the components caused by the machining of these difficult-to-machine materials are also important for the resulting component performance, especially when used in highly stressed safety-relevant components as discussed in [5].

According to most recent work focusing the connection between machining condition and service performance of components, it was summed by Yue et al. [6] that in most cases theoretical approaches or modelling is not necessarily leading to the intended result, but is preferably be clarified by means of experimental data. This is to be further emphasized by the issue of manufacturing conditions due to welding generation. Furthermore, these issues of reliable achievement of a stress-appropriate surface integrity are also linked to a series of questions and research priorities that have evolved in recent years. Wojciechowski et al. particularly include as current major problems and directions concerning hard-to-machine materials novel production and machining techniques as well as production or machining optimization methods and novel measurement or characterization techniques [7].

The microstructure of additive manufactured components differs significantly in comparison to those produced conventionally, e.g. by means of as cast or wrought alloys [8]. In particular this concerns the size of grains and the type, shape and size of precipitates, and therefore specific impacts on the performance in machining processes have to be anticipated. Moreover, the surface morphology of the generated component and the possibilities to control or predict it certainly will play a significant role in the selection of optimal finishing processes and machining conditions or strategies in the future, as has been shown by Jozwik et al. for the laser-based powder bed fusion AM process at Ti-6Al-4V [9]. However, investigations into the combination of additive and machining manufacturing processes are recently primarily based on laser technologies. In addition to laser-based processes, welding processes with high production and application rates and high industrial availability are essential for economical use. Hoefer et al., therefore, experimentally compared the plasma powder deposition welding (plasma transferred arc, PTA) and the gas metal arc welding (GMAW) processes for the application in AM of components [10]. Both processes are the most important candidates for high productivity AM. Besides, significant higher deposition rate and material utilization of wire arc additive manufacturing (WAAM) in comparison to PTA processes a very high level of development, e.g. modified process variants are available for this technology. In addition to achieving the mechanical-technological properties, the stresses in the component during additive manufacturing must be minimized to prevent failures during component production. In many cases, the final mechanical properties of components made of NiCrMo alloys generated by welding are adjusted by post weld heat treatment (PWHT), whereby the residual stresses in the component are almost entirely released [11].

The repair or welding generation of components with high build-up rates combined with the generation of defined contours and functional surfaces for complex geometries requires finishing machining, for metals usually with a geometrically defined cutting edge. For finishing processes, the surface quality and in particular the residual stresses introduced as well as property changes in the peripheral zone are crucial $[5,6]$. Ulutan and Ozel concluded that the resulting surface integrity depends on the complex interaction of topographic (roughness, waviness, including defects), metallurgical (microstructural alteration) and mechanical (residual stresses, strain hardening) influences [12], see Fig. 1a. Especially in the case of materials for highly stressed components, such as $\mathrm{Ni}$ alloys, machinability is often very challenging due to high strength and toughness as well as the associated high cutting forces, frequently occurring hard precipitation, low heat conduction and the affinity for strain hardening. As tool wear is an issue in machining of hard-to-machine alloys, this was investigated by Singh et al. for IN718 [13]. The authors provided two evolutionary optimization methods for machining conditions to reduce tool wear for milling of IN718 under different cooling conditions. It was found that minimum quantity lubrication (MQL) exhibited the best performance and that cutting speed has dominant influence regarding flank wear. Nieslony et al. analysed the cutting forces and surface morphology in dependence of different tools for drilling explosively clad Ti-steel plates [14]. It could be shown that dependent on the applied 
a) external features: chemistry, roughness, waviness, form, lay, texture, pits, tears, laps, burrs ...

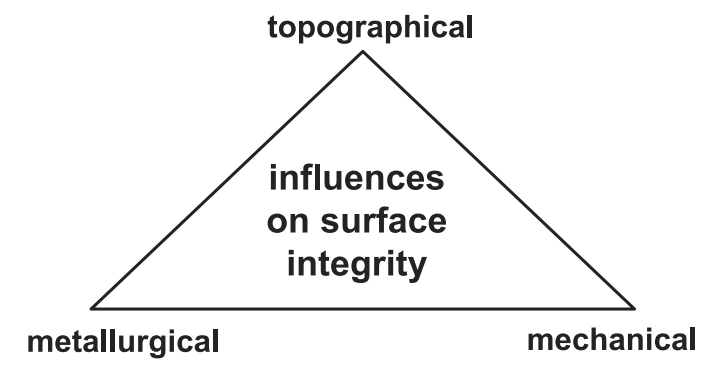

internal features: microstructure, hardness, cracks, residual stresses, transformations, plastic deformation, white layers ...

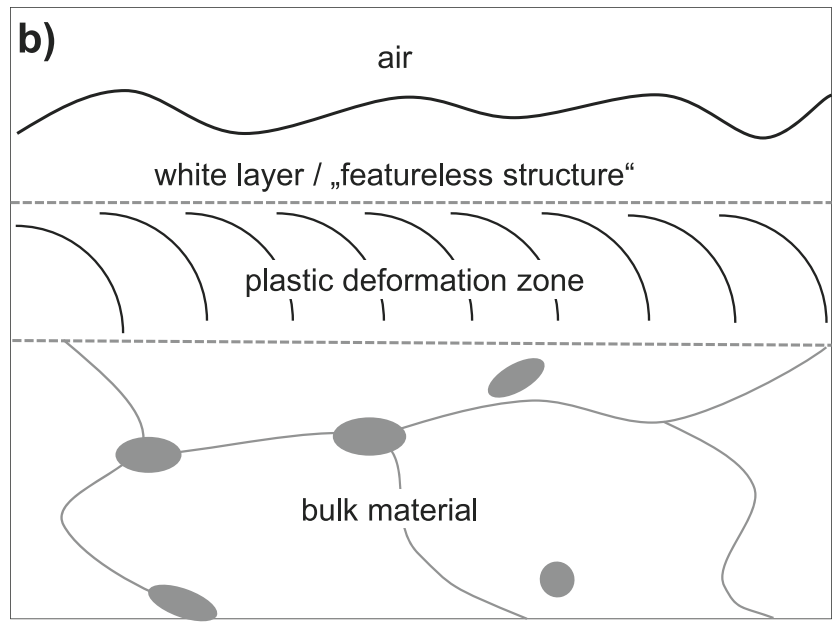

Fig. 1 External, internal features and influences after machining constituting the surface integrity $[12,19]$ (a), surface morphology of a white layer according to $[15,17]$ (b)

tools, a change in the microstructure and, therefore, material properties has a significant influence on the process and on the surface morphology. Besides defects and external features of the surface, unfavourable milling process conditions may lead to unwanted subsurface morphology, called white layer formation, as for instance shown in [1517], and an extensive a zone of plastic deformation, e.g. found by Dargusch et al. [18], see Fig. 1b. Today, these tremendous challenges are increasingly addressed by hybrid machining processes, which was shown by M'Saoubi et al. for aerospace materials [19]. In [20] it was found that for grinding of silica glass the superposition of the cutting motion with ultrasonic oscillation in the axial direction is suitable in order to minimize process forces, temperatures and tool wear and to increase the surface quality. Several other authors reported similar results for ultrasonic-assisted grinding of glass and ceramics. The authors of [21] provide an overview of a number of these results. Hence, recently this process is state-of-the-art for grinding of many innovative hard and brittle materials.
Moreover, Khanna et al. observed a microchipping effect and thereby decreased surface roughness for ultrasonicassisted turning of a NiCrCo alloy (Nimonic-90) in comparison to a conventional turning process [22]. Similar positive effects have been found for ultrasonic-assisted milling (USAM). Ni et al. achieved a significant reduction of the cutting forces and improvement of the surface quality when applying USAM at $\mathrm{Ti}-6 \mathrm{Al}-4 \mathrm{~V}$ in comparison to conventional milling process [23]. It could be shown that the force reduction is the result of a superimposed movement in the range of the oscillation amplitude (up to $14 \mu \mathrm{m}$ ) of the cutting edge, which is mainly in the cutting direction and therefore reduce the net cutting time and the toolworkpiece contact rate. Similar results could be shown by Rinck et al. likewise at Ti-6Al-4V [24]. It has also been observed that USAM provides beneficial results in the milling of fibre reinforced plastics [25]. The authors found no reduction in cutting force, but the best workpiece quality regarding the quality criterion fibre pull-out and significantly decreased dust generation when using USAM. In [26] the effect of USAM for face milling of Ni alloy IN718 on the surface integrity was analysed. The authors observed almost no reduction in cutting forces and no considerable benefit for surface quality. However, it has to be noted that ultrasonic oscillation of the cutting edge in the investigated case of face milling was perpendicular to the cutting direction. The oscillation mainly occurs along the axis of the cutting edge for face milling; thus, the positive effects, as described by $\mathrm{Ni}$ et al. [23], were almost entirely suppressed. Still, the influence of USAM processes on the surface integrity of difficult-to-machine materials such as $\mathrm{NiCrMo}$ alloys has not yet been the subject of research yet. As a result of the effects and interactions on the surface and component integrity of the special microstructures of additively manufactured components due to subsequent machining processes, further knowledge is required for highly economical manufacturing and repair technologies for highly stressed components. Investigations in this area have not been carried out to date but are urgently required.

Furthermore, recent research focussed rather on the microstructural changes induced due to machining, in most cases omitting the effects on the milling process due to the component manufacturing-related changes in the microstructure. Therefore, particularly due to the increasing relevance of additive manufacturing steps, an intensified consideration of the characteristic microstructures resulting from the generative component welding process is crucial, and the impact on subsequent finishing processes for the machining of defined surfaces is analysed in this study. Moreover, it should not be left unmentioned that finishing operations, typically ball nose end milling, have not yet been the subject of systematic investigations for USAM of difficult-to-machine materials either, and are therefore 
considered in more detail in this study. Although, in several studies for conventional ball end milling optimal parameters were found. Concerning process forces and vibrations for precision ball end milling of hardened steel an optimal inclination angle of $45^{\circ}$ was found [27]. Wang et al. analysed ball end milled specimens from IN718 and showed that the state of residual stresses is strongly affected by cutting conditions. The authors indicated that thermal effects due to milling process induce rather tensile stresses and mechanical effects rather compressive stresses into the component surface [28]. However, with the application of ball end milling tools, a specific optimization of the cutting process may be enabled for the most efficient utilization of the beneficial effects due to USAM process depending on the inclination or lead angle of the tool. This issue was not investigated up to date.

A NiCrMo alloy with high strength at high temperatures and at the same time very high resistance to corrosion is IN725 (UNS N07725), with specifications given in [29] by the producer Special Metals Corp. As Shoemaker shows in [30], IN725 is therefore being increasingly used in many different applications, such as aerospace, plant engineering and construction, e.g. petrochemistry, or even for use in seawater. In its modified form, INCO-WELD filler metal 725NDUR provides an excellent weldability and is highly suitable for welding repairs, coatings and generative manufacturing steps using GMAW processes. In the present work, the influences of subsequent ablative machining steps by conventional and ultrasonic-assisted milling on the peripheral zone properties of IN725 samples generated by wire arc additive manufacturing were therefore analysed with the aim of achieving safe and economical component production. Two main aspects, first the reduction of cutting forces and the resulting residual stresses and second the reduction of an unwanted subsurface morphology change due to ultrasonic-assisted milling, will be shown. For this purpose, investigations were carried out on the quantitative influence of the manufacturing parameters on the cutting forces and the essential aspects of surface integrity by means of instrumented milling experiments.

\section{Experimental}

For the experiments, IN725 by means of solid welding wire (INCO-WELD 725NDUR) were welded to a sandblasted steel plate $(\mathrm{S} 355$, length $=200 \mathrm{~mm} \times$ width $=50 \mathrm{~mm}$ $\times$ thickness $=20 \mathrm{~mm}$ ). The parameters for the automated GMAW process are listed in Table 1.

The chemical composition of the as-welded IN725 specimen was analysed using optical emission spectroscopy (OES) and can be found in Table 2. The typical transverse mechanical properties of alloy INCO-WELD 725NDUR
Table 1 Parameters for GMA welding of INCO-WELD 725NDUR

\begin{tabular}{lll}
\hline $\begin{array}{l}\text { Welding } \\
\text { speed }\end{array}$ & $\begin{array}{l}\text { Wire feeding } \\
\text { speed } \\
45 \mathrm{~cm} / \mathrm{min}\end{array}$ & $\begin{array}{l}\text { Distance } \\
\text { between lines } \\
4.5 \mathrm{~m} / \mathrm{min}\end{array}$ \\
$\begin{array}{ll}\text { Welding current } & \text { Shielding }\end{array}$ \\
and voltage & gas & $\begin{array}{l}\text { Interpass } \\
\text { temperatures } \\
178 \mathrm{~A}\end{array}$ \\
$21.1 \mathrm{~V}$ & $97.5 \% \mathrm{Ar}$, & 100 to \\
\hline
\end{tabular}

after recommended PWHT at room temperature could be achieved and are given in Table 3.

After welding of several layers to ensure a weld thickness of approx. $10 \mathrm{~mm}$, the weld was cut in six 20-mmlong specimens, cf. Fig. 2a. The weld metal was than separated from the base plate and machined to cuboids $(28 \mathrm{~mm} \times 18 \mathrm{~mm} \times 8 \mathrm{~mm})$ in the as-welded condition, $\mathrm{cf}$. Fig. 2b. The cuboid specimens were then heat treated after the rouging process, which is also recommended in the processing instructions of the material producer before finishing machining. The PWHT was performed in the following steps, as also recommended by the material producer:

- Solution annealing for $1 \mathrm{~h}$ at $1038^{\circ} \mathrm{C}$,

- Aging for $8 \mathrm{~h}$ at $732^{\circ} \mathrm{C}$ and $8 \mathrm{~h}$ at $620^{\circ} \mathrm{C}$.

For microstructure analysis before and after PWHT perpendicular to the weld direction, two cross-section specimens were cut out of the weld. After the PWHT, machining experiments were carried out using finishing milling of the upper side of the cuboid specimens in the DMGMORI DMU 65 five-axis machining centre, which was modified for ultrasound-assisted milling. Figure $2 \mathrm{c}$ shows an overview of the experimental setup. A dynamometer by Kistler was used to measure the cutting forces $\left(F_{\mathrm{f}}\right.$, feed force; $F_{\mathrm{fN}}$, normal feed force and $F_{\mathrm{p}}$, passive force). The ultrasonic oscillation during milling is initiated by piezo actuators in the milling tool adaptor in the direction of tool rotation. The maximum amplitude of the oscillation is approx. $10 \mu \mathrm{m}$ at resonance frequency. The resonance frequency depends mainly on the weight of the milling tool and the tool holder and was determined for the finishing milling tests at $f_{\mathrm{US}}=(47.8 \pm 0.2) \mathrm{kHz}$. The sampling rate of cutting force measurement was $7184 \mathrm{~Hz}$ and, thus, much smaller unable to acquire ultrasonic oscillation.

Table 2 Chemical composition of the tested weld metal (INCOWELD 725NDUR, in \%

\begin{tabular}{lllllll}
\hline $\mathrm{Ni}$ & $\mathrm{Cr}$ & $\mathrm{Mo}$ & $\mathrm{Mn}$ & $\mathrm{Nb}$ & $\mathrm{Ti}$ & $\mathrm{Fe}$ \\
\hline 54.6 & 24.8 & 5.9 & 2.0 & 2.1 & 2.2 & Bal. \\
\hline
\end{tabular}


Table 3 Typical transverse mechanical properties of alloy 725 NDUR after PWHT at room temperature

\begin{tabular}{lllll}
\hline $\begin{array}{l}\text { Yield strength } \\
\text { in MP }\end{array}$ & $\begin{array}{l}\text { Tensile strength } \\
\text { in MPa }\end{array}$ & $\begin{array}{l}\text { CVN Impact } \\
\text { in J }\end{array}$ & $\begin{array}{l}\text { Elongation } \\
\text { in } \%\end{array}$ & $\begin{array}{l}\text { Reduction in area } \\
\text { in \% }\end{array}$ \\
\hline 909 & 1181 & 57 & 25 & 30 \\
\hline
\end{tabular}

A solid carbide radius cutter with a diameter of $14 \mathrm{~mm}$ was used as milling tool. The ball nose end mill according to DIN 6527L (FIRE 3050, type N by Gühring) is characterized by four flutes, right hand cutting direction and no cutting edge radius. The milling parameters were selected according to the tool manufacturer's recommendation for the material (group S) to be machined, see Table 4. In all tests, the tool was tilted at an angle of $45^{\circ}$ to the feed direction and of $45^{\circ}$ to the feed perpendicular direction, see Fig. 3. In addition to the use of ultrasonic assistance while milling, the step over $a_{\mathrm{e}}$ and the use of cooling lubricant were varied in the tests.
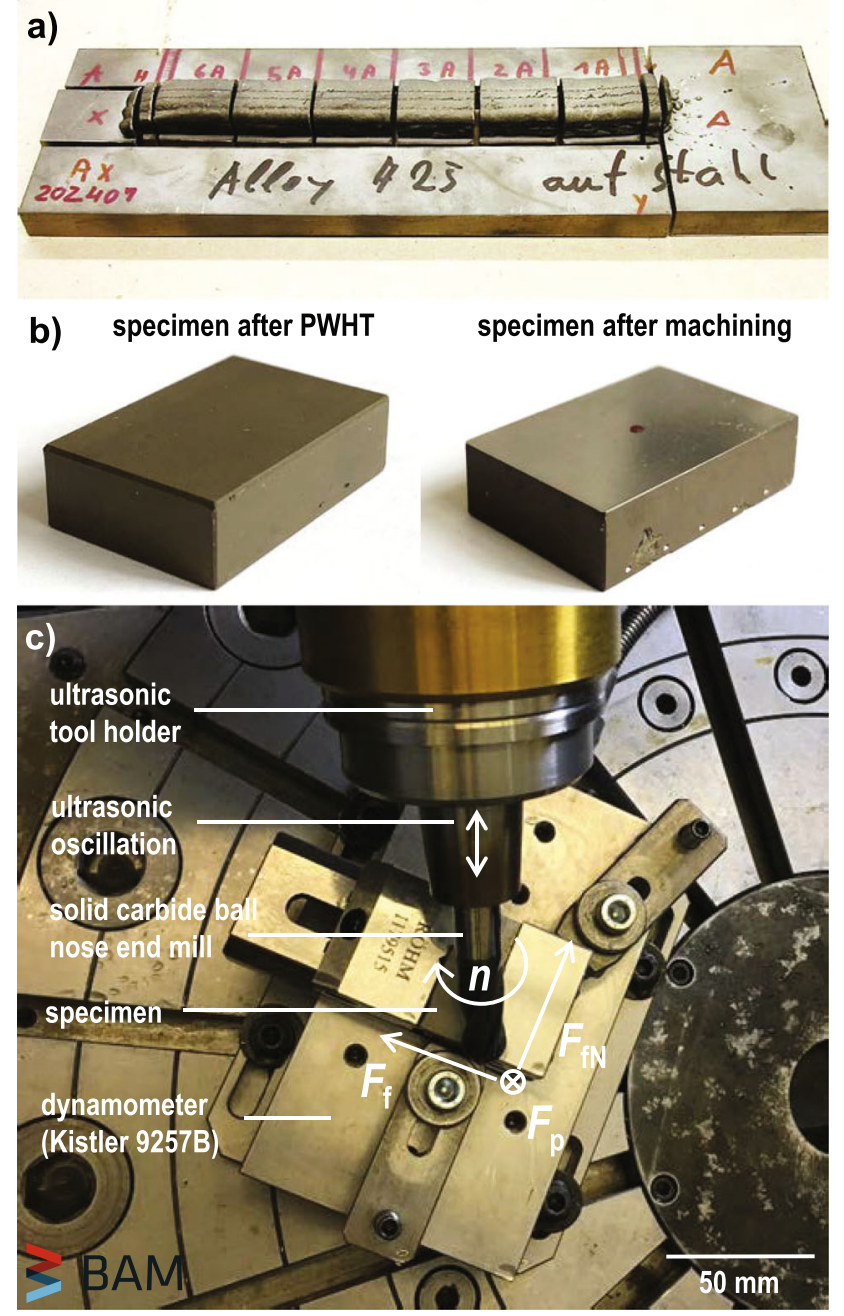

Fig. 2 Welded specimens on steel substrate plate (a), the cuboid specimens after PWHT and after finishing milling (b), and overview picture of the experimental setup for milling experiments (c)
After milling experiments the surface integrity of the specimens was analysed. Topography was investigated for roughness using a contact profilometer and for surface condition/defects using light microscopy and scanning electron microscope (SEM). The subsurface morphology and metallurgy were analysed at cross sections using SEM and electron backscatter diffraction (EBSD) analyses, respectively.

EBSD measurements were performed with a dual beam microscope Helios Nanolab 600 (FEI) using a CHANNEL 5 EBSD system of the company Oxford. The images were taken at $20 \mathrm{kV}$ accelerating voltage and a probe current of $0.69 \mathrm{nA}$. For the SEM images, a low-kV high-contrast detector (vCD), which detects high-energy backscattered electrons (BSE), was applied. The image contrast in BSE images is mainly determined by the element composition and topography of the surface. In addition, BSE images show a high orientation contrast which can be used to visualize the grain structure of the material.

The mechanical influences on the surface and subsurface were examined by means of residual stress analyses using X-ray diffraction (XRD), see Fig. 4. The penetration depth of this measuring method is only $5 \mu \mathrm{m}$. By electro polishing of the specimens, the measurement of depth profiles of the residual stresses could be derived. Polishing parameters were $20 \mathrm{~s}$ at $20 \mathrm{~V}$, which resulted in an ablated layer thickness of approx. $10 \mu \mathrm{m}$.

\section{Results}

\subsection{Weld microstructure}

Figure 5 shows the microstructure of alloy 725NDUR overlay welds in comparison before and after the PWHT. Comparing Fig. 5a and $\mathrm{b}$ reveals that the dendritic structure has largely dissolved in the microstructure after PWHT. Furthermore, some grain boundaries with precipitates had formed. In the bright areas, precipitates are obvious. Typically, the structure of the precipitation-hardening IN725 after heat treatment consists of an FCC matrix with finely dispersed $\gamma$ ' and $\gamma$ " precipitates. The $\gamma$ ' precipitates are $\mathrm{Ni}_{3}(\mathrm{Al}, \mathrm{Ti})$ in an ordered FCC $\mathrm{L}_{2}$ crystal structure. The $\gamma$ " phase is typically $\mathrm{Ni}_{3}(\mathrm{Nb}, \mathrm{Al}, \mathrm{Ti})$ and has an ordered tetragonal $\mathrm{DO}_{22}$ crystal structure [31]. Both $\gamma$ ' and $\gamma$ "' precipitates are soluble for elements such as $\mathrm{Co}, \mathrm{Cr}, \mathrm{Nb}$ and Mo. Besides a subordinate occurrence of $\eta$ and $\delta$ phases, 
Table 4 Cutting parameters and parameter variation for machining experiments

\begin{tabular}{|c|c|c|c|c|c|c|}
\hline \multirow{2}{*}{$\begin{array}{l}\text { Lead angle } \lambda=-45^{\circ} \\
\text { Tilt angle } \theta=-45^{\circ} \\
\text { Test no. }\end{array}$} & \multicolumn{3}{|c|}{$\begin{array}{l}\text { Cutting speed } v_{\mathrm{c}}=42 \mathrm{~m} / \mathrm{min} \\
\text { Depth of cut } a_{\mathrm{p}}=0.2 \mathrm{~mm}\end{array}$} & \multicolumn{3}{|c|}{$\begin{array}{l}\text { Feed per tooth } f_{\mathrm{Z}}=0.031 \mathrm{~mm} \\
\text { Ultrasonic frequency tooth } f_{\mathrm{US}}=(47.8 \pm 0.2) \mathrm{kHz}\end{array}$} \\
\hline & 1 & 2 & 3 & 4 & 5 & 6 \\
\hline Ultrasonic assistance & No & Yes & No & Yes & No & Yes \\
\hline Cooling lubricant & Yes & Yes & Yes & Yes & No & No \\
\hline Step over $a_{\mathrm{e}}$ in $\mathrm{mm}$ & 0.1 & 0.1 & 0.3 & 0.3 & 0.3 & 0.3 \\
\hline
\end{tabular}

according to literature, precipitates of carbides such as MC ( $\mathrm{Ti}$ and $\mathrm{Nb}$-rich) and $\mathrm{M}_{23} \mathrm{C}_{6}$ ( $\mathrm{Cr}$-rich) are known and can be observed particularly distinctly when comparing Fig. 5c and $\mathrm{d}$ in the microstructure after PWHT. The granular structure of the welded material can be made visible via EBSD, Fig. 5e, f. In comparison to rolled products, the grain size is large, due to the additive manufacturing process of welding and the PWHT. Major defects in the welded material have not been observed.

\subsection{Machining process}

During machining of all specimens, the occurring machining forces were measured. Figure 6 shows the cutting forces during a milling test (test 1 ) for one machining pass (a) and one tool rotation (b). The cutting forces are distinguished into feed force, normal feed force and passive force. The forces correspond to the coordinate system of the specimen for $x, y$ and $z$, respectively. A force peak occurs when a tool cutting edge engages the surface. Due to the four cutting edges of the tool, four force peaks are caused by one

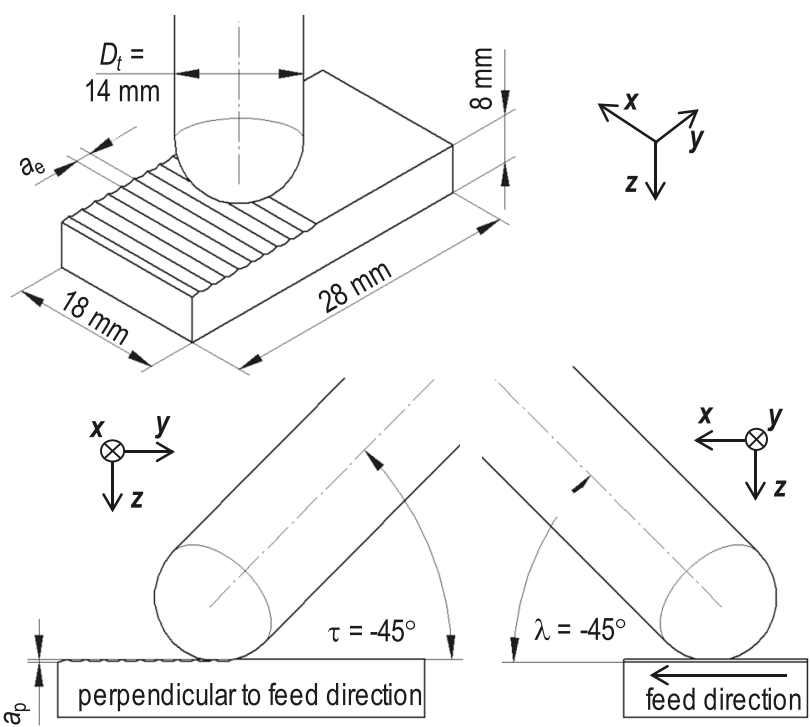

Fig. 3 Technical drawing, specimen and tool dimensions and setup for finishing milling experiments tool rotation. The greatest amount of force is caused by the passive force in the $z$-direction, since the cutting edge of the tool penetrates the workpiece surface from above in down cutting. At the same time, down cutting also causes an increase in force against the $x$-direction, because the cutting movement (i.e. the peeling of the chip) takes place against the feed direction. Therefore, the feed forces have a negative sign. The normal feed forces in the $y$-direction are mainly caused by the inclined penetration into the tool surface and the inclined peeling cut of the cutting edge of the ball nose end mill. The passive forces are the highest in comparison to the feed and normal feed forces, as the maximum reaction force is encountered during the process of penetration of the cutting edge of the tool into the workpiece surface. However, the amounts or the proportions of the force components depend strongly on the tilt and the lead angle of the milling tool as described by [32]. For the same configuration of tool and workpiece, in particular tilt and lead angle as well as tool conditions, the cutting forces are comparable for each machining test. In these investigations, therefore, the resulting forces of the three force components were determined by means of Eq. 1, cf. Fig. 6c.

$F_{\text {res }}=\sqrt{F_{\mathrm{p}}^{2}+F_{\mathrm{fN}}^{2}+F_{\mathrm{f}}^{2}}$

\begin{tabular}{|c|c|}
\hline \multicolumn{2}{|c|}{ measuring mode $\sin ^{2} \psi$} \\
\hline radiation & $\mathrm{MnKa}$ \\
\hline detector & Linear solid state \\
\hline diffraction line & 311 \\
\hline $2 \theta$ angle & $156^{\circ}$ \\
\hline collimator $\varnothing$ & $3 \mathrm{~mm}$ \\
\hline tube power & $30 \mathrm{kV} / 6.7 \mathrm{~mA}$ \\
\hline$\Psi$-tilting & $0^{\circ}$ to $\pm 45^{\circ}$ \\
\hline$\psi$-Step & 9 \\
\hline measuring time & $3 \mathrm{~s}$ to $5 \mathrm{~s}$ \\
\hline
\end{tabular}

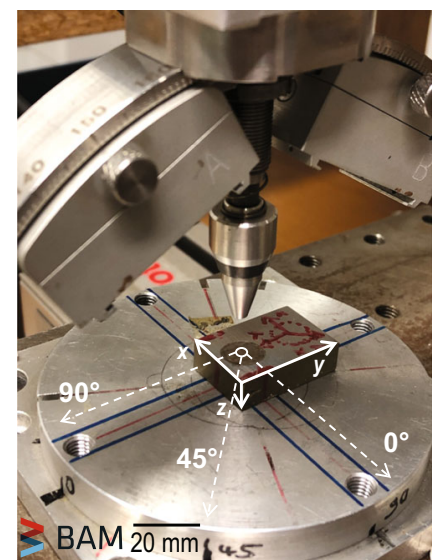

Fig. 4 Parameters for XRD residual stress analyses of the finish milled specimen surfaces; measurement directions: $0^{\circ}, 45^{\circ}$ and $90^{\circ}$ to feed direction 

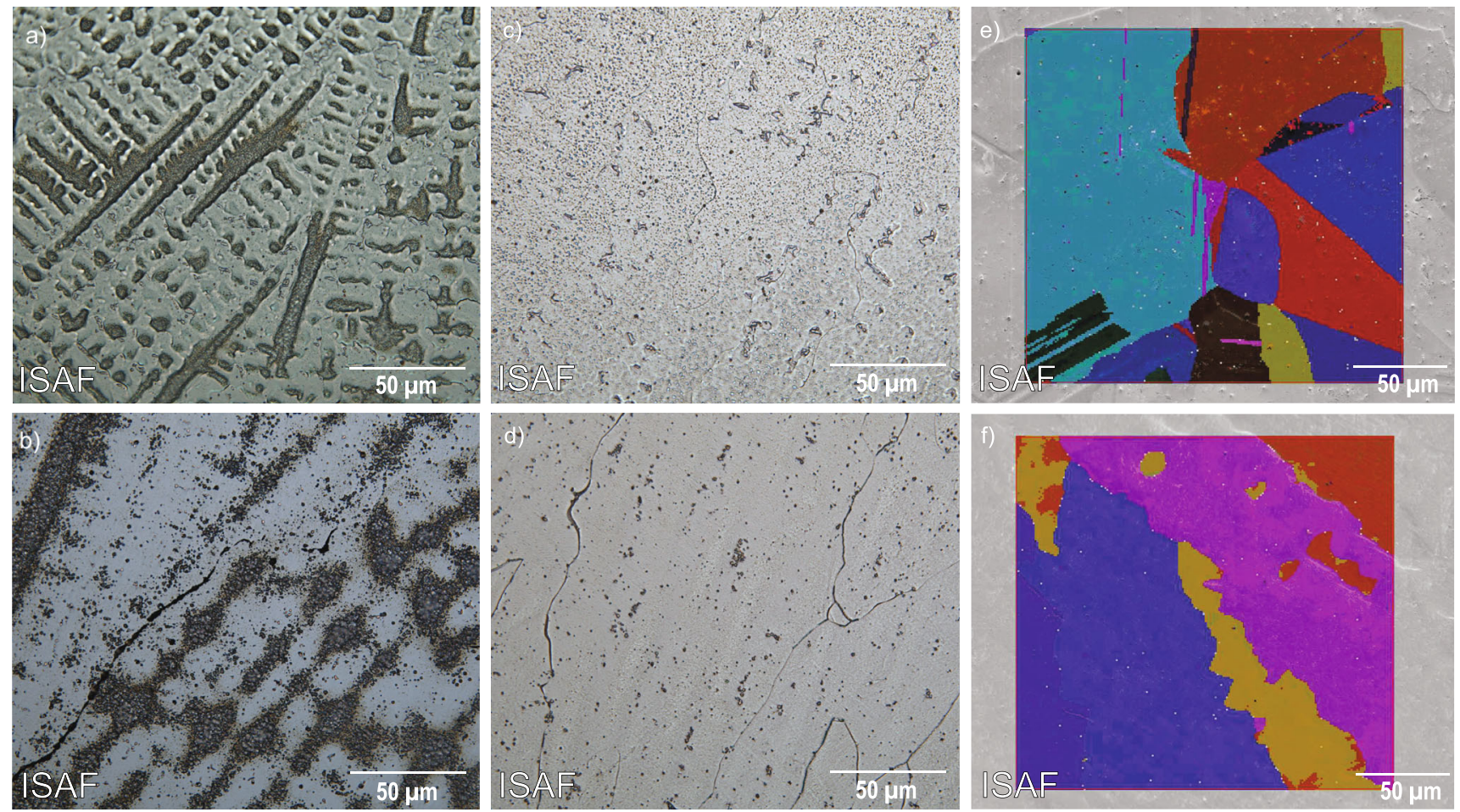

Fig. 5 Weld microstructure: before (a, c) and after PWHT (b, d), EBSD mapping of weld microstructure after PWHT at two different regions of the weld $(\mathbf{e}, \mathbf{f})$; modified V2A-etchant $(\mathbf{a}, \mathbf{b})$, Adler etchant $(\mathbf{c}, \mathbf{d})$

It was observed that cutting forces are significantly lower for ultrasonic-assisted milling, see Fig. 7, for all three force components and the resulting cutting force in comparison between tests 3 and 4 .

As described in [23], the force reduction is primarily due to the reduced contact time caused by the ultrasonic oscillation frequency of the cutting edge being multiple times higher than the cutting speed. Another effect of the oscillation is a reduced friction coefficient between the cutting edge and the workpiece surface.

Due to the same tilt and lead angle and tool condition in the entire test matrix, the mean values of the resulting cutting forces could be determined for all tests to compare the influences of the milling parameters on the cutting
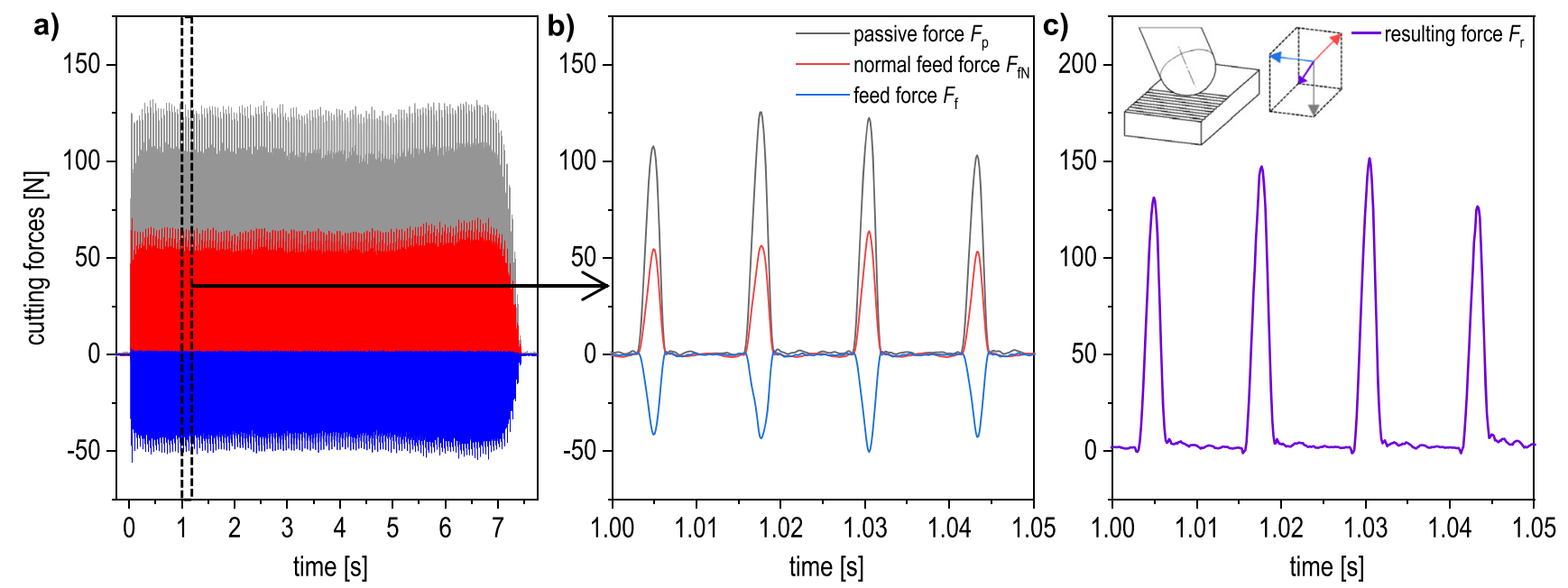

Fig. 6 Cutting forces $F_{\mathrm{p}}, F_{\mathrm{f}}, F_{\mathrm{fN}}(t)$ during a milling test (test 1 , with cooling lubricant, no ultrasonic assistance, $a_{\mathrm{e}}=0.1 \mathrm{~mm}$ ) for one machining pass (a), one tool rotation (b) and resulting cutting force $F_{\text {res }}(t)(\mathbf{c})$ 

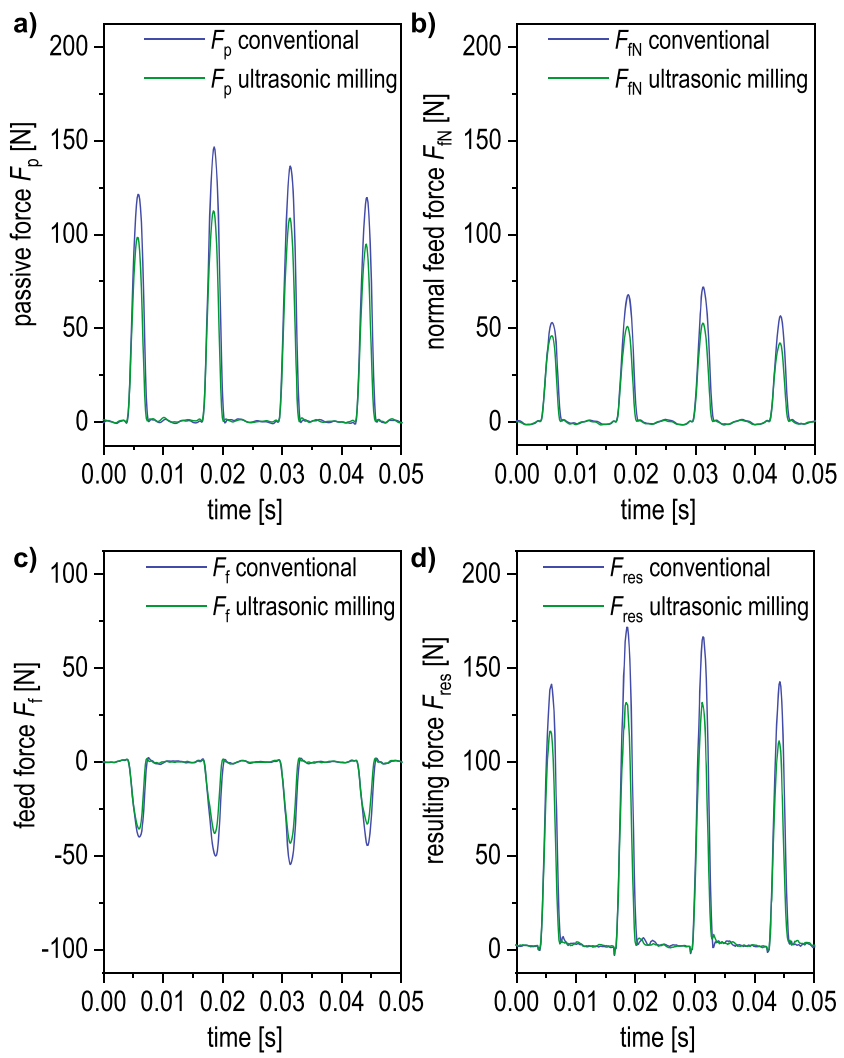

Fig. 7 Comparison of passive forces $F_{\mathrm{p}}(\mathbf{a})$, normal feed forces $F_{\mathrm{fN}}(\mathbf{b})$ and feed forces $F_{\mathrm{f}}(\mathbf{c})$ and the resulting forces $F_{\text {res }}(\mathbf{d})$ for two milling experiments (tests 3 and 4) without and with ultrasonic assistance

forces. For this purpose, an analysis of the individual peaks of all cutting edge engagements measured in the tests has been carried out. The average of the maximum resulting cutting force $F_{\mathrm{r} \text {,max }}$ and the mean cutting force during the engagement time $F_{\mathrm{r}, \mathrm{m}}$ was determined for all engagements using Eq. 2, cf. Fig. 8a,

$F_{\mathrm{r}, \max }=\frac{\sum F_{\mathrm{r}, \text { max }}(\text { peak })}{N_{\text {peak }}} \quad$ and $\quad F_{\mathrm{r}, \mathrm{m}}=\frac{\sum \frac{A_{F \mathrm{r}}}{t_{\mathrm{e}}}(\text { peak })}{N_{\text {peak }}}$

taking in to account the amount of cutting edge engagements $N_{\text {peak }}$. Hence, the area under the force peaks $A_{\text {Fr }}$ was divided by the true engagement time $t_{\mathrm{e}}$ of the cutting edge (width of the force peaks) disregarding the time with no engagement of the tool $t_{\mathrm{n}}$ during the time of tool rotation $t_{\mathrm{r}}$ for the complete measured data set. This allowed a direct quantitative comparison between the measured cutting forces for all measured milling tracks with a high statistical reliability, see Fig. 8b, c. It reveals that ultrasonic assistance during milling results in all cases to a significant reduction of the cutting forces. The decrease in cutting force is lower if a small step over is applied. For a step over of $a_{\mathrm{e}}=0.3 \mathrm{~mm}$ and applied cooling lubricant, the force reduction is approx. $11 \%$. The absence of cooling lubricant leads to higher cutting forces in case of conventional milling. With ultrasonic assistance especially at dry milling, a remarkable reduction of mean and maximum cutting forces can be achieved as it is shown in Fig. 8c. Hence, the cutting forces decreased by approx. $20 \%$ compared to conventional milling. In case of no ultrasonic assistance, the mean cutting forces are about $10 \mathrm{~N}$ higher for dry machining in comparison to the application of cooling lubricants.

\subsection{Surface integrity}

Surface defects and topography The first significant differences between the milled samples have been already observed when examining the morphology using light
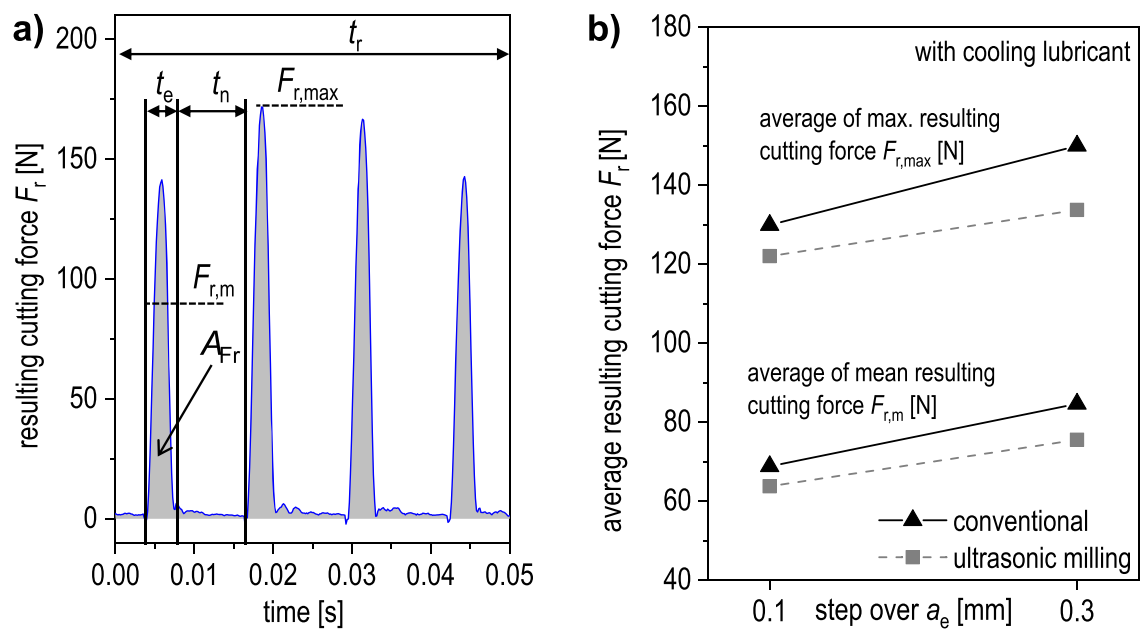

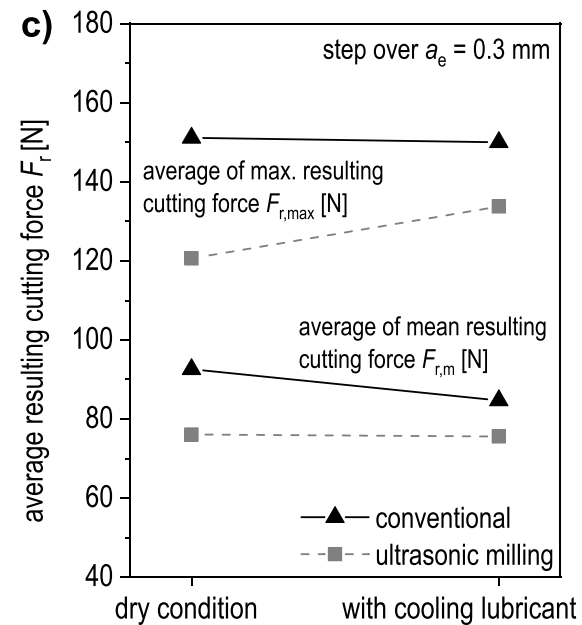

Fig. 8 Schematic for determination of the tool engagement time $t_{\mathrm{e}}$ and of the area under the force peaks $A_{\mathrm{Fr}}$ for calculation of average cutting forces (a); average resulting max. resulting forces $F_{\text {r,max }}$ (standard deviation $s=9.65 \mathrm{~N}$ ) and average resulting mean resulting forces $F_{\mathrm{r}, \mathrm{m}}$ (standard deviation $s=6.15 \mathrm{~N}$ ) vs. step over $a_{\mathrm{e}}$ and application of ultrasonic assistance (b) and vs. application of cooling lubricant and of ultrasonic assistance (c) 

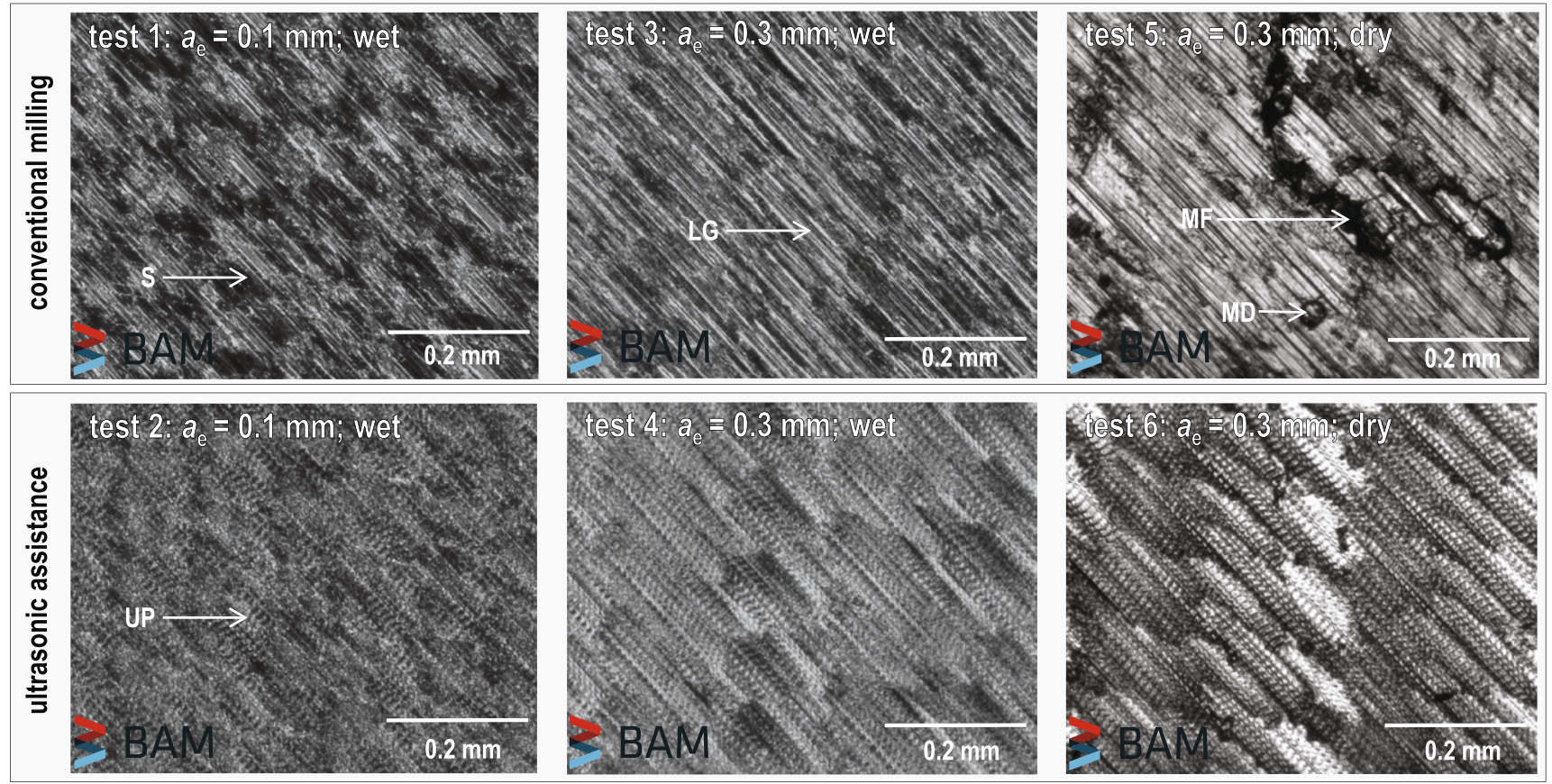

Fig. 9 Morphology of specimen surfaces for all milling experiments using light microscopy (F, flash; LG, long grooves; SM, smeared material; MF, microfracture; MD, metal debris; S, streak; UP, ultrasonic pattern)

microscopy, as shown in Fig. 9. Conventional milling with low step over $\left(a_{\mathrm{e}}=0.1 \mathrm{~mm}\right)$ leads to the formation of finer streaks, whereas increased step over results in longer grooves in the workpiece surface due to scraping by the cutting edge of the milling tool. The omission of cooling lubricants in conventional milling also leads to microcracks and adhesion of chips and to an overall high density of defects on the surface. In the case of an additional superposition with ultrasound oscillation during milling, an ultrasonic pattern is visible on all samples but almost no streaks or
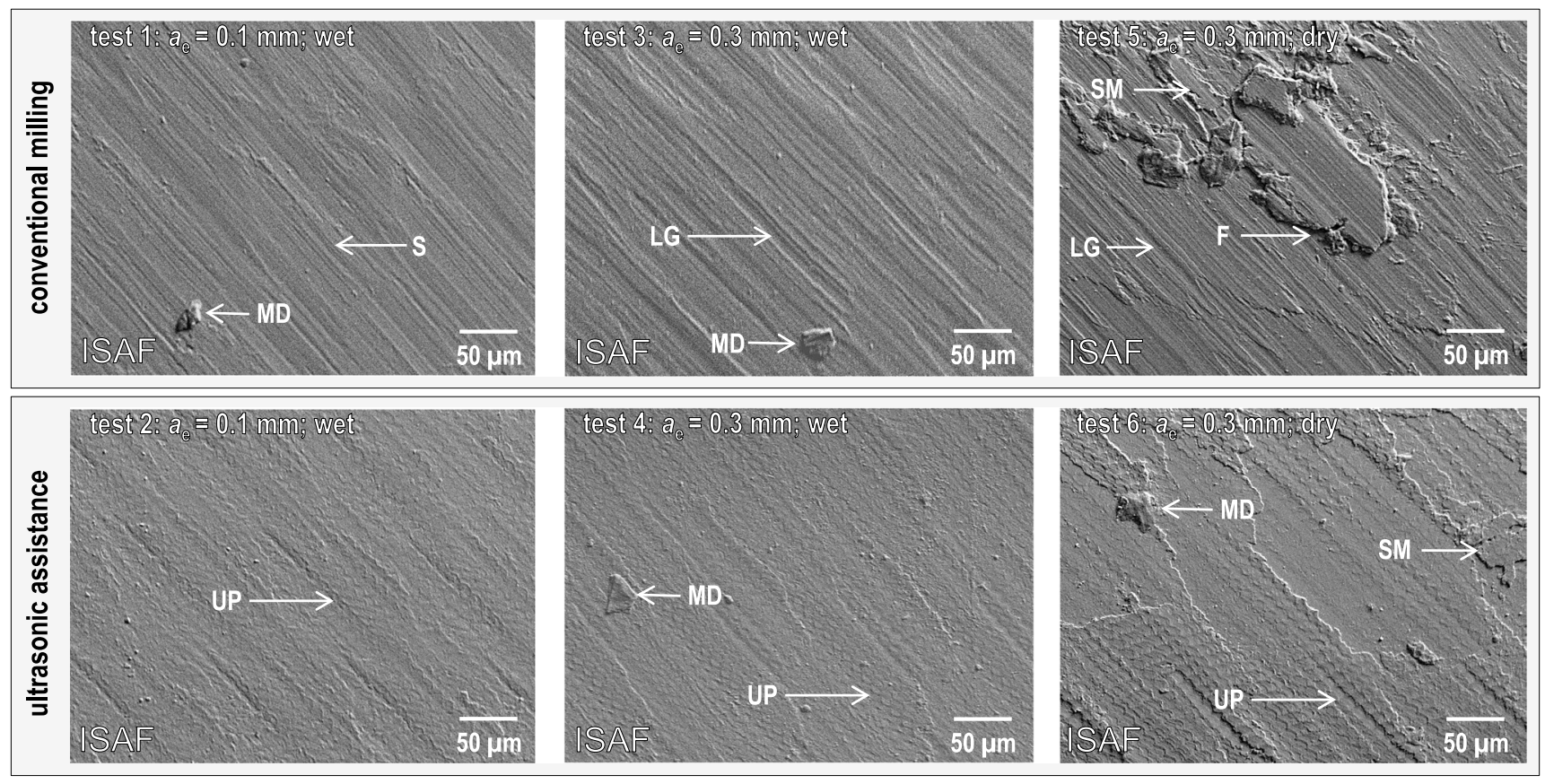

Fig. 10 Investigation of surface defects of specimen surfaces for all milling experiments using SEM (F, flash; LG, long grooves; SM, smeared material; MF, microfracture; MD, metal debris; S, streak; UP, ultrasonic pattern) 
grooves on the surfaces. The characteristic ultrasonic pattern is due to the combined oscillation of the cutting edge of the tool towards the workpiece surface and laterally to cutting direction during cutting. Which relative movement prevails depends on the angle of incidence of the radius cutter to the workpiece surface and on the tool geometry. Ultimately, the pattern is due to the fact that in this case the frequency of the ultrasonic oscillation is a multiple in relation to the spindle or cutting speed. It should also be noted that, in the finishing milling experiment without cooling lubricant, by using ultrasonic assistance a surface with a fairly low defect density is achieved in comparison to the conventional milling processes.

Figure 10 shows examples for surface defects found on the milled surfaces of the samples using SEM investigation. As with the light microscopic images in Fig. 9, the stripe formation and grooves become more intense with increasing step over and the number and size of defects increases with dry milling. In ultrasonic-assisted milling, the ultrasonic pattern is visible instead of streaks and grooves. Metal debris and smeared material can be observed on the surface of the dry milled sample. However, microfracture and large areas of smeared material and flashes, as in conventional milling, do not occur. Here, too, a lower density and size of defects due to ultrasonic milling could be observed.

Regarding the roughness of the specimen surfaces, it can be observed that step over value and the use of cooling lubricant have significant influence. Higher step over and dry milling increase $R_{\mathrm{a}}$ and $R_{\mathrm{t}}$. Considering the use of ultrasonic assistance during milling, the roughness values are at a similar height with a tendency to lower values, primarily for omission of cooling lubricant, see Fig. 11. After dry milling, also a considerable lower standard deviation for the $R_{\mathrm{a}}$ and $R_{\mathrm{t}}$ values is present when USAM was applied, which could be traced back to the lower density of severe surface defects compared to conventional milled specimens.

Subsurface morphology The subsurface area of the two test specimens milled under wet condition with a high step over is shown in Fig. 12a and b. It reveals that without the ultrasonic assistance subsurface deformations and possible transformation induced twinning are detectable. Furthermore, a pronounced surface layer with a uniform microstructure as described by other authors, i.e. by Umbrello [15], as "featureless structure" can be found indicating white layer formation, cf. Fig. 12c. Applying ultrasonic-assisted milling, the extent of plastic deformation zones is significantly smaller and no pronounced white layer formation occurs. This allows the implication that there are different properties of the surface as a result of the two milling process conditions. Especially, the smaller extent of the plastic deformation zone without white layer formation
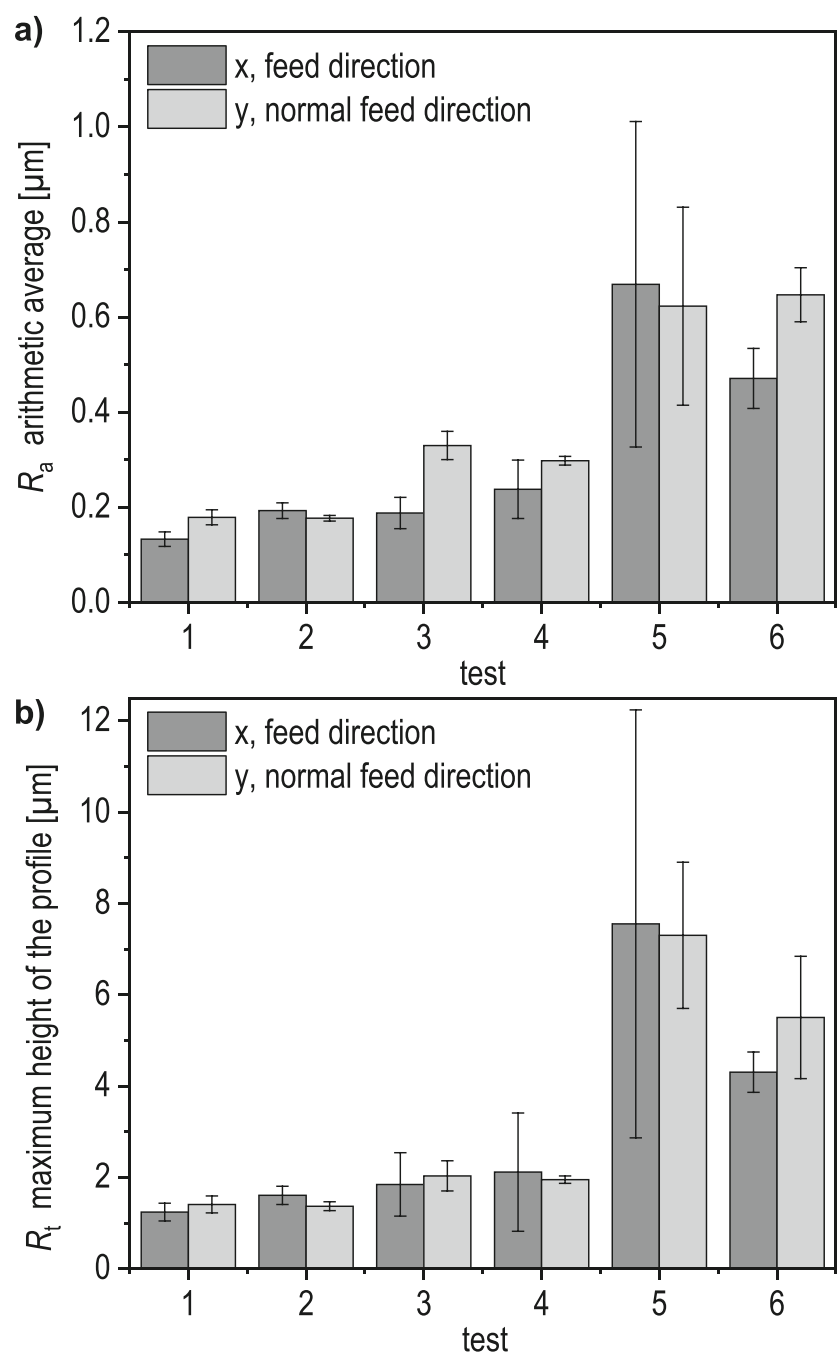

Fig. 11 Measured roughness $R_{\mathrm{a}}(\mathbf{a}), R_{\mathrm{t}}(\mathbf{b})$ and standard deviation of specimen surfaces

provides a significantly higher surface integrity avoiding potential premature crack initiation and propagation, which is crucial, for instance in the face of elevated corrosive stresses affecting the components. Figure $12 \mathrm{~d}$ shows the subsurface grains observed with EBSD mapping. Due to the subsurface deformation and the microstructure within the featureless structure, the measurement directly beyond the surface is hardly possible, which was observed by several other authors analysing white layer formation, as described by Thakur and Gangopadhyay [33]. The decreasing amount of points that could be assessed is evident towards the machined edge specimen cross section, especially in the proposed white layer formation.

Residual stresses In Table 5 all residual stress values of the finish milled specimens are shown. From the stresses analysed in three directions $\left(\sigma_{\mathrm{x}}^{\mathrm{rs}}, \sigma_{\mathrm{y}}^{\mathrm{rs}}\right.$ and $\left.\sigma_{45^{\circ}}^{\mathrm{rs}}\right)$, the principal 

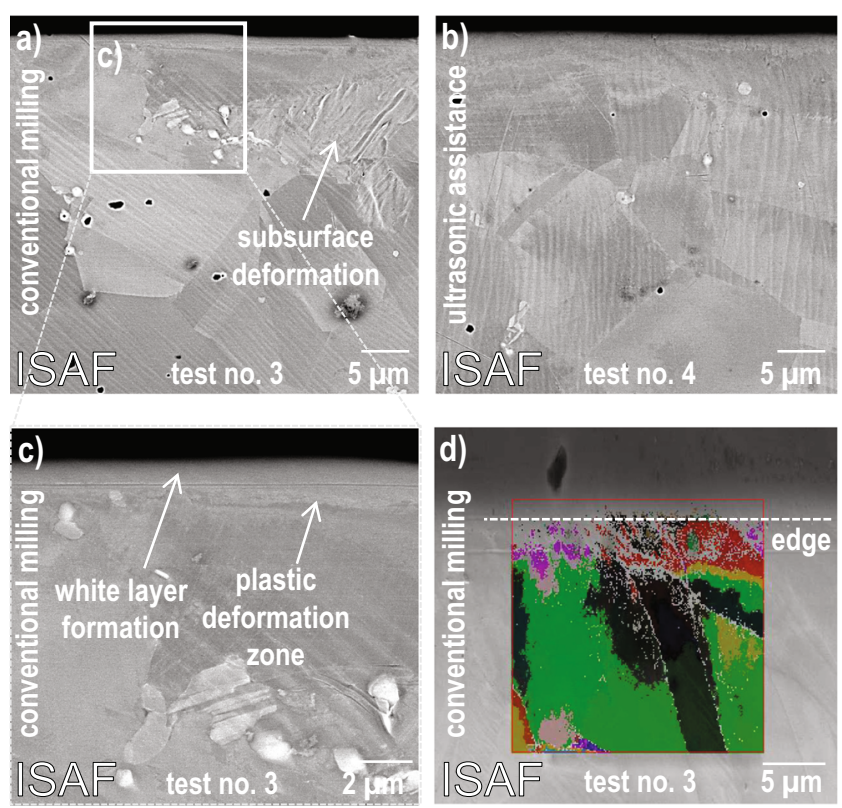

Fig. 12 SEM image of cross sections of milled specimens of test 3 (a) and test 4 (b); detail of surface plastic deformation zone and white layer of test 3: SEM analysis (c) and EBSD mapping (d)

residual stresses $\left(\sigma_{1}^{\mathrm{rs}}\right.$ and $\left.\sigma_{2}^{\mathrm{rs}}\right)$ were calculated, using Eqs. 3 and 4:

$$
\begin{aligned}
\sigma_{1}^{\mathrm{rs}}= & \frac{\left(\sigma_{\mathrm{x}}^{\mathrm{rs}}+\sigma_{\mathrm{y}}^{\mathrm{rs}}\right) / 2}{\sigma_{2}^{\mathrm{rs}}=} \\
& +\sqrt{\left(\sigma_{45^{\circ}}^{\mathrm{rs}}-\frac{\sigma_{\mathrm{x}}^{\mathrm{rs}}+\sigma_{\mathrm{y}}^{\mathrm{rs}}}{2}\right)^{2}+\left(\frac{\sigma_{\mathrm{x}}^{\mathrm{rs}}+\sigma_{\mathrm{y}}^{\mathrm{rs}}}{2}-\sigma_{\mathrm{y}}^{\mathrm{rs}}\right)^{2}} \\
& -\sqrt{\left(\sigma_{45^{\circ}}^{\mathrm{rs}}-\frac{\sigma_{\mathrm{x}}^{\mathrm{rs}}+\sigma_{\mathrm{y}}^{\mathrm{rs}}}{2}\right)^{2}+\left(\frac{\sigma_{\mathrm{x}}^{\mathrm{rs}}+\sigma_{\mathrm{y}}^{\mathrm{rs}}}{2}-\sigma_{\mathrm{y}}^{\mathrm{rs}}\right)^{2}}
\end{aligned}
$$

The initial residual stress level of the heat-treated specimens is max. $\sigma_{1}^{\mathrm{rs}}=18 \pm 14 \mathrm{MPa}$. It is obvious that the residual stresses transverse to the feed direction are lower than in feed direction. The highest values can be found $45^{\circ}$ to feed direction, which also represents the approximately cutting direction due to the configuration of tool and workpiece, cf. cutting marks in Figs. 9 and 10. Overall, the residual stresses are decreased for the lower step over of $a_{\mathrm{e}}=0.1 \mathrm{~mm}$ (tests 1 and 2) in comparison to step over of $a_{\mathrm{e}}=0.3 \mathrm{~mm}$ (tests 3 to 6 ).
For further comparison, Fig. 13a shows an effect diagram of the maximum principal stress values $\sigma_{1}^{\text {rs }}$ as a function of the use of ultrasonic assistance and step over of $a_{\mathrm{e}}$ for cooling lubricant condition. It could be observed that the lowest residual stress level is induced into the surface if ultrasonic assistance was applied during milling for smaller step over values.

The highest principal residual stress can be found for conventional milling without cooling lubricant application with a step over of $a_{\mathrm{e}}=0.3 \mathrm{~mm}$, cf. Fig. 13b. Ultrasonic assistance is capable to reduce these tensile residual stresses at the surface by factor 2 . For tests 1 and 2 , the depth profiles of the principal residual stresses $\sigma_{1}^{\mathrm{rs}}(z)$ are compared in Fig. 13c. For both milled specimens, the highest tensile residual stresses are directly at the surface. Note that the measuring depth via XRD for this material and the given tube power is of approx. $5 \mu \mathrm{m}$ and decreases with increasing inclination angle. The XRD analysis system enables a depth correction for stress profile measurement considering high stress gradients in depth direction $z$ due to the depth information and measurement results of the different inclination angles. For conventional milling the tensile stresses are significantly higher at over $400 \mathrm{MPa}$ compared to the value for milling with ultrasonic assistance at approx. $170 \mathrm{MPa}$. The residual stresses decrease at a distance from surface of $10 \mu \mathrm{m}$ to compressive values for both cases. With increasing depth, the residual stresses remain in compressive range for milling with ultrasonic assistance and vary around the transition between compressive and tensile range for the conventionally milled specimen. It is observed that starting from the depth of $20 \mu \mathrm{m}$, the residual stresses increase again. For the conventionally milled specimen, the increase proceeds to $40 \mu \mathrm{m}$ depth and to $130 \mathrm{MPa}$ tensile residual stress. It may be assumed that this is due to subsurface deformation, as the increase also occurs for the with ultrasonic assistance milled specimen, but only reaches $-80 \mathrm{MPa}$ compressive residual stresses and only occurs to a depth of $30 \mu \mathrm{m}$. Considerable compressive residual stresses are present at a depth of $50 \mu \mathrm{m}$ for both specimens, approx. $-300 \mathrm{MPa}$ for the specimen milled with ultrasonic assistance and approx. $-150 \mathrm{MPa}$ for the

\begin{tabular}{|c|c|c|c|c|c|c|c|c|c|}
\hline Test & no. & & Initial & 1 & 2 & 3 & 4 & 5 & 6 \\
\hline$\sigma_{\mathrm{x}}^{\mathrm{rs}}$ & In feed direction & {$[\mathrm{MPa}]$} & $4 \pm 10$ & $16 \pm 15$ & $-59 \pm 16$ & $22 \pm 33$ & $58 \pm 18$ & $149 \pm 19$ & $-26 \pm 25$ \\
\hline$\sigma_{\mathrm{y}}^{\mathrm{rs}}$ & Normal to feed dir. & {$[\mathrm{MPa}]$} & $-3 \pm 15$ & $-60 \pm 18$ & $-248 \pm 8$ & $-49 \pm 14$ & $-175 \pm 11$ & $135 \pm 24$ & $-129 \pm 42$ \\
\hline$\sigma_{45^{\circ}}^{\mathrm{rs}}$ & $45^{\circ}$ to feed dir. & {$[\mathrm{MPa}]$} & $18 \pm 12$ & $212 \pm 18$ & $2 \pm 18$ & $271 \pm 19$ & $81 \pm 12$ & $408 \pm 33$ & $189 \pm 32$ \\
\hline$\sigma_{1}^{\mathrm{rs}}$ & Max. principal stress & {$[\mathrm{MPa}]$} & $18 \pm 14$ & $215 \pm 19$ & $28 \pm 15$ & $273 \pm 26$ & $123 \pm 14$ & $408 \pm 30$ & $194 \pm 37$ \\
\hline$\sigma_{2}^{\mathrm{rs}}$ & Min. principal stress & {$[\mathrm{MPa}]$} & $-18 \pm 14$ & $-259 \pm 19$ & $-336 \pm 15$ & $-300 \pm 26$ & $-241 \pm 14$ & $-124 \pm 30$ & $-349 \pm 37$ \\
\hline
\end{tabular}
conventionally milled specimen. Presumably, these residual compressive stresses are due to balancing residual stresses

Table 5 Measured surface residual stresses and calculated principal residual stresses of the finish milled specimens 

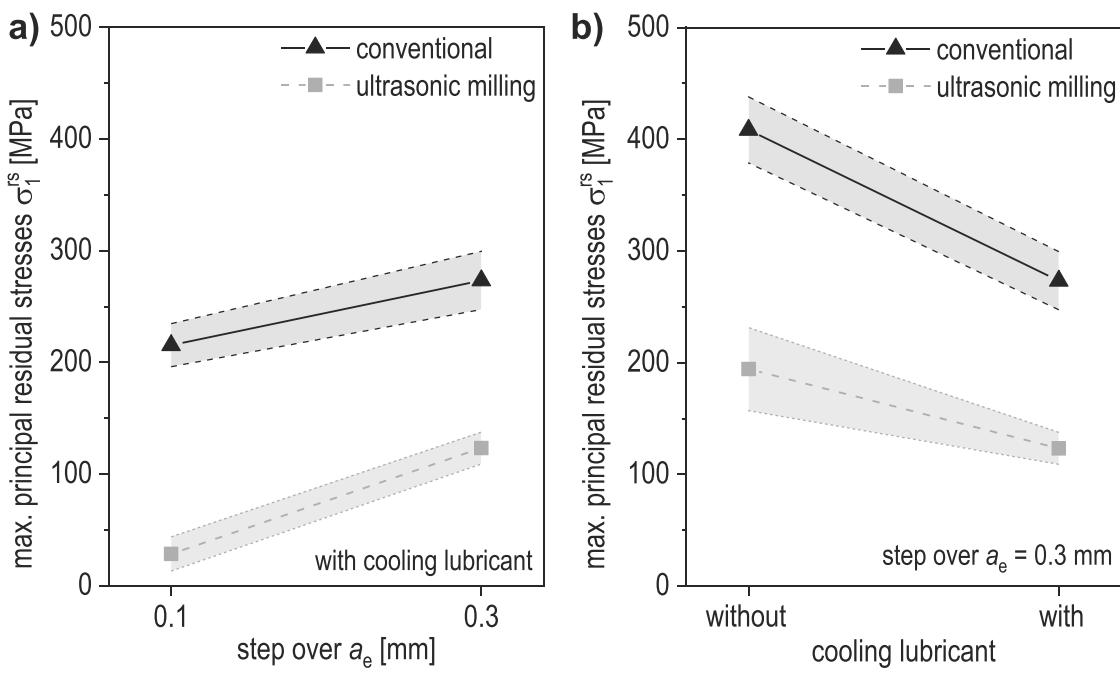

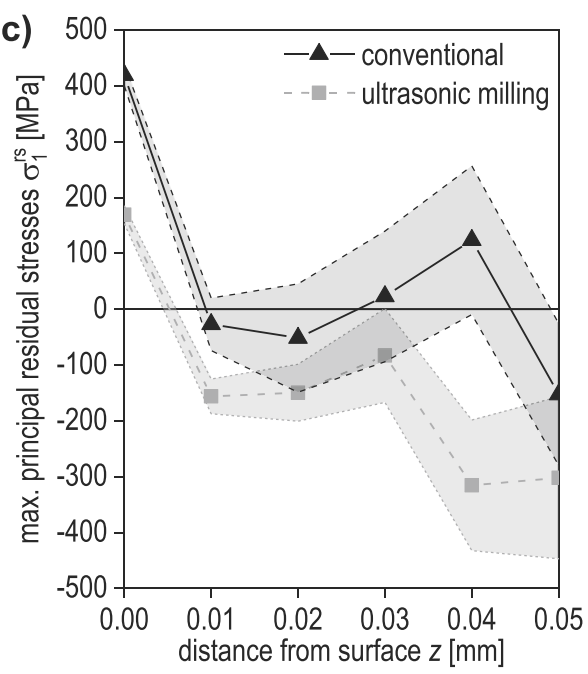

Fig. 13 Maximum principal residual stresses $\sigma_{1}^{\text {rs }}$ vs. step over $a_{\mathrm{e}}$ and application of ultrasonic assistance (a) and vs. application of cooling lubricant and of ultrasonic assistance (b); max. principal residual stress profile in direction of the specimen thickness $\sigma_{1}^{\text {rs }}(z)$ after finishing milling (tests 1 and 2) with and without ultrasonic assistance (c)

application of ultrasonic assistance. Especially in case of omitting cooling lubricants during milling, a significant improvement regarding topography and surface defects is evident. Consistent with other authors [18-21, 23, 24], this is to be attributed to a reduced friction in the removal process between tool and workpiece. Another explanation for this is also described by other authors as microchipping effect [22]. In association with a decrease in total time of the cutting edge engagement at surface due to the component of the superimposed ultrasonic movement of tool tip in cutting direction, ultimately, the result is a lower thermal effect and, therefore, a lower strain and plastification at

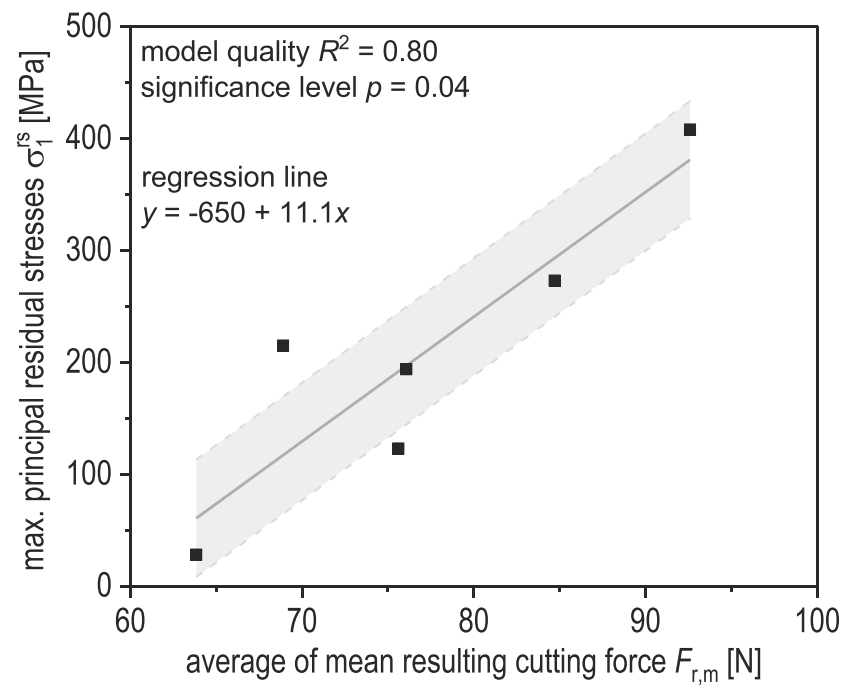

Fig. 14 Maximum principal residual stresses $\sigma_{1}^{\text {rs }}$ vs. average of mean resulting cutting force $F_{\text {res,m }}$ for all milling tests 
the surface. Furthermore, the component of the ultrasonic movement of the oscillating tool respectively the cutting edge in direction of the workpiece surface leads to a rather increased densification of the peripheral zone, which could also be shown by means of higher compressive residual stresses below the surface or subsurface. Similar findings for mechanical influencing of the surface by the cutting tool were reported by Wang et al. for conventional ball end milling of IN718 [28].

The observed effect of enhanced surface integrity should also be reflected in the performance of finish milled AM components. It is assumed that the lowered residual stresses as well as the thermo-mechanical influence on the microstructure in the peripheral zone and the substantially diminished extent of the white layer together with the lowered defect density will significantly increase the performance and safety of the components and improve the service life [5, 6]. A confirmation of this should be the focus of detailed investigations. In such research, it is also advantageous if the surface morphology can be determined and evaluated very exactly by means of high-precision measurement technology after both the $\mathrm{AM}$ and the finishing milling processes [9]. It could be shown that the greatest differences in the resulting surface integrity occurred for dry milling experiments regarding the application of USAM. Therefore, also future analyses regarding this should consider different cooling strategies, and process temperature measurements in comparison between ultrasonic-assisted and conventional ball end milling. As the tool wear was not considerable in this study due to the sample size and was also not considered in depth, it is recommended for further investigations to examine this in more detail by means of new evaluation or optimization methods and different cooling strategies, similar to the investigations by Sigh et al. [13], in order to be ultimately able to prove a high economic efficiency for these processes. Besides that, the presented results should be verified in a cross-material study for example at hard-to-machine $\mathrm{CoCr}$ and $\mathrm{FeNi}$ alloys in the next steps. Furthermore the implementation of optimization methods into the milling process [13, 22, 27] should extend the service life of the tools. Apart from that the milling experiments should be connected to more extend to the surface morphologies achieved by the additive manufacturing steps to establish optimized finishing milling strategies and machining conditions [9]. Moreover, it is of great importance that the cutting edge kinematics in the process are also considered, e. g. by mathematical modelling, in order to have a better understanding of ultrasonic-assisted milling, especially for the complex case of ball nose end milling tools. In this study inclination angles of the tool of $45^{\circ}$ were used, as other authors reported optimal results regarding machining process and surface morphology [27]. In one of the next steps, it will be a major task to find optimized inclination angle ranges for best ultrasonic efficiency for contour milling, according to [27, 28, 32].

This should be also an important contribution for a correlation of the process conditions and the subsurface morphology by further EBSD analyses of the machined specimens $[5,12,33]$. Although, literature supports the presented results for several conventional manufactured materials of the subsurface deformations [16]. In the present study, these effects were initially shown for additively welded and post weld heat-treated specimens. However, it has to be noted that additive manufacturing due to welding results in rather inhomogeneous and anisotropic materials and properties. Therefore, the occurring deformations and changes in the microstructure may also be influenced by the local properties or property gradients of the welded material [8]. Hence, further targeted experiments should likewise focus on the specific behaviour due to local inhomogeneity. Besides different machinability characteristics and, therefore, unstable or discontinuous machining conditions at different locations or orientations of a specimen or component, this inhomogeneity may also influence the residual stress assessment. As the difference in occurring residual stresses within deposited weld metal is commonly known, this should be considered for further residual stresses evaluation, especially in a condition without PWHT. And there would be another problem being taken into account, a significant component distortion or deformation due to the release of residual stresses during machining $[4,34]$.

Further investigation will also focus other materials, which are hard-to-machine, like mentioned, $\mathrm{CoCr}$ alloys and austenitic FeNi alloy to prove a cross-material benefit of the ultrasonic-assisted milling for additively manufactured or repair welded components. On the basis of the results of other authors which found beneficial effects for ultrasonicassisted milling for several hard-to-machine $\mathrm{Ti}, \mathrm{Ni}$ and steel alloys, e.g. [19, 24, 26], it can be strongly assumed that these processes are also suitable for other materials. Another promising application may be the machining of, for example, new and innovative material classes such as intermetallic $\mathrm{FeAl}$ (iron aluminide alloys) [35].

\section{Conclusions}

In the present study, machining by means of contour milling with ball end milling tool of an wire arc additively manufactured NiCrMo alloy (IN725) was investigated. In the experiments for the first time ultrasonic-assisted milling was analysed for this material in comparison to a conventional milling process applying different milling 
parameters. The cutting forces and the influence on the resulting surface integrity were analysed. The following conclusions can be drawn:

(1) The resulting cutting force revealed to be significantly reduced if ultrasonic assistance was applied in the milling process. Milling condition omitting usage of cooling lubricant exhibited the greatest reduction of the mean resulting cutting forces by approx. 20\% applying USAM compared to conventional milling. In accordance to other authors [23, 24], this is presumably to trace back on a reduced contact time of the cutting edge with the component surface and, therefore, less friction during the cutting process when applying USAM.

(2) The superimposed ultrasonic oscillation of the tool with a frequency of approx. $47.8 \mathrm{kHz}$ under otherwise identical machining conditions results in an improved surface morphology. Particularly under dry milling condition, a considerably lower defect density and, thus, approx. 30\% lower values regarding roughness parameters revealed for USAM compared to conventional milling.

(3) In comparison to conventional milling, USAM revealed positive effects on subsurface morphology due to a significant reduction in the extent of the severely deformed areas. Additionally, the rather detrimental white layer formation could be diminished to a thickness in the range of the detection limit.

(4) Lower tensile residual stresses with a reduction of up to $200 \mathrm{MPa}$ or $60 \%$ on the top surface of the sample machined with ultrasonic assistance are observable even under machining conditions using cooling lubricant.

(5) A significant linear correlation between the mean resulting cutting forces and tensile residual stresses on the top surface was found. This initially indicates the relationship between milling-induced mechanical loading of the surface and residual stress evolution for comparative studies of ultrasonic-assisted and conventional milling. Note that thermal stresses due to milling by temperature measurements were not considered in this investigation and have to be analysed in further studies for an in-depth understanding of this phenomenon.

(6) In comparison to conventional milled specimens, also increased compressive residual stresses in subsurface areas are evident. This overall significant reduction of the manufacturing-related residual stress level in the peripheral zone has the potential to inhibit the initiation or formation of cracks or even to prevent stress corrosion cracking during subsequent component service. Moreover, this could be emphasized by the reduction of the extend of severely deformed areas and white layer formation.

It should be noted, however, that these results are initially applicable to the materials and conditions used in these milling analyses and are not simply transferable. However, the high comparability with other studies using different parameters and materials indicates that a good transferability can be achieved by means of some additional studies. Overall, the results indicate that an ultrasonicassisted milling has significant beneficial effects on the surface quality, the subsurface morphology and the overall manufacturing-related residual stress state, which was revealed for ball end milled AM specimens of a hardto-machine NiCrMo alloy for the first time. Hence, besides the transferability of the results to other hard-tomachine materials or AM processing routes, optimization studies regarding inclination angles and other basic milling parameters are necessary for the next steps. With these initial results, systematic analyses and an extended number of parameters, materials, or even specifically altered microstructures due to AM process conditions are to be elaborated in future work. Further investigations should also focus on the potential improvement of the safety and performance as well as service life of finish milled additively manufactured, repaired or modified components from NiCrMo alloy due to the enhanced surface integrity.

Funding Open Access funding enabled and organized by Projekt DEAL. This research did not receive any specific funding agencies in the public, commercial, or not-for-profit sectors.

\section{Declarations}

Ethical approval We hereby state that the present work is in compliance with the ethical standards.

Consent to participate We hereby consent to participate.

Consent for publication We hereby consent to publication.

Conflict of interest The authors have no relevant financial or nonfinancial interests to disclose.

Open Access This article is licensed under a Creative Commons Attribution 4.0 International License, which permits use, sharing, adaptation, distribution and reproduction in any medium or format, as long as you give appropriate credit to the original author(s) and the source, provide a link to the Creative Commons licence, and indicate if changes were made. The images or other third party material in this article are included in the article's Creative Commons licence, unless indicated otherwise in a credit line to the material. If material is not included in the article's Creative Commons licence and your intended use is not permitted by statutory regulation or exceeds the permitted use, you will need to obtain permission directly from the copyright holder. To view a copy of this licence, visit http://creativecommons. org/licenses/by/4.0/. 


\section{References}

1. Frazier WE (2014) Metal additive manufacturing: a review. J Mater Eng Perform 23:1917-1928. https://doi.org/10.1007/s116 65-014-0958-z

2. Boess V, Denkena B, Wesling V, Kaierle S, Rust F, Nespor D, Rottwinkel B (2016) Repairing parts from nickel base material alloy by laser cladding and ball end milling. Prod Eng 10:433-441. https://doi.org/10.1007/s11740-016-0690-7

3. Malekipour E, El-Mounayri H (2018) Common defects and contributing parameters in powder bed fusion am process and their classification for online monitoring and control: a review. Int J Adv Manuf Technol 95:527-550. https://doi.org/10.1007/ s00170-017-1172-6

4. Nadammal N, Cabeza S, Mishurova T, Thiede T, Kromm A, Seyfert C, Farahbod L, Haberland C, Schneider JA, Portella PD, Bruno G (2017) Effect of hatch length on the development of microstructure, texture and residual stresses in selective laser melted superalloy inconel 718. Mater Des 134:139-150. https://doi.org/10.1016/j.matdes.2017.08.049

5. M'Saoubi R, Outeiro JC, Chandrasekaran H, Dillon OW, Jawahir IS (2008) A review of surface integrity in machining and its impact on functional performance and life of machined products. Int $J$ Sustain Manuf 1(1/2):203-236. https://doi.org/10.1504/ijsm.2008.019234

6. Yue C, Gao H, Liu X, Liang S (2018) Part functionality alterations induced by changes of surface integrity in metal milling process: a review. Appl Sci 8(12). https://doi.org/10.3390/app8122550

7. Wojciechowski S, Krolczyk GM, Maruda RW (2020) Special issue: advances in hard-to-cut materials: manufacturing, properties, process mechanics and evaluation of surface integrity. Materials (Basel) 13(3). https://doi.org/10.3390/ma13030612

8. Dang J, Cai X, Yu D, An Q, Ming W, Chen M (2019) Effect of material microstructure on tool wear behavior during machining additively manufactured Ti6Al4V. Arch Civ Mech Eng 20(1). https://doi.org/10.1007/s43452-019-0007-7

9. Jozwik J, Ostrowski D, Milczarczyk R, Krolczyk GM (2018) Analysis of relation between the 3D printer laser beam power and the surface morphology properties in Ti-6Al-4V titanium alloy parts. J Braz Soc Mech Sci Eng 40(4). https://doi.org/10.1007/ s40430-018-1144-2

10. Hoefer K, Haelsig A, Mayr P (2018) Arc-based additive manufacturing of steel components-comparison of wire- and powder-based variants. Weld World 62:243-247. https://doi.org/ 10.1007/s40194-017-0527-9

11. Davis J (2000) Nickel, cobalt, and their alloys. p 442

12. Ulutan D, Ozel T (2011) Machining induced surface integrity in titanium and nickel alloys: a review. Int $\mathrm{J}$ Mach Tools Manuf 51:250-280. https://doi.org/10.1016/j.ijmachtools.2010.11.003

13. Singh G, Gupta MK, Mia M, Sharma VS (2018) Modeling and optimization of tool wear in MQL-assisted milling of Inconel 718 superalloy using evolutionary techniques. The Int J Adv Manufact Technol 97(1-4):481-494. https://doi.org/10.1007/s00170018-1911-3

14. Nieslony P, Cichosz P, Krolczyk GM, Legutko S, Smyczek D, Kolodziej M (2016) Experimental studies of the cutting force and surface morphology of explosively clad Ti-steel plates. Measurement 78:129-137. https://doi.org/10.1016/j.measurement.2015. 10.005

15. Umbrello D (2012) Analysis of the white layers formed during machining of hardened AISI 52100 steel under dry and cryogenic cooling conditions. Int J Adv Manuf Technol 64(5-8):633-642. https://doi.org/10.1007/s00170-012-4073-8
16. Jin D, Liu Z (2013) Damage of the machined surface and subsurface in orthogonal milling of FGH95 superalloy. Int J Adv Manuf Technol 68(5-8):1573-1581. https://doi.org/10.1007/s00 170-013-4944-7

17. Bosheh SS, Mativenga PT (2006) White layer formation in hard turning of $\mathrm{H} 13$ tool steel at high cutting speeds using CBN tooling. Int J Mach Tools Manuf 46(2):225-233. https://doi.org/ 10.1016/j.ijmachtools.2005.04.009

18. Dargusch MS, Zhang MX, Palanisamy S, Buddery AJM, StJohn DH (2008) Subsurface deformation after dry machining of grade 2 titanium. Adv Eng Mater 10(1-2):85-88. https://doi.org/10.1002/adem.200700233

19. M'Saoubi R, Axinte D, Soo SL, Nobel C, Attia H, Kappmeyer G, Engin S, Sim WM (2015) High performance cutting of advanced aerospace alloys and composite materials. CIRP Ann Manuf Technol 64:557-580. https://doi.org/10.1016/j.cirp.2015.05.002

20. Jian-hua Z, Li-ying W, Fu-qiang T, Yan Z, Zhi W (2015) Modeling study on surface roughness of ultrasonic-assisted micro end grinding of silica glass. Int J Adv Manuf Technol 86(14):407-418. https://doi.org/10.1007/s00170-015-8181-0

21. Feucht F, Ketelaer J, Wolff A, Mori M, Fujishima M (2014) Latest machining technologies of hard-to-cut materials by ultrasonic machine tool. Proc CIRP 14:148-152. https://doi.org/10.1016/ j.procir.2014.03.040

22. Khanna N, Airao J, Gupta MK, Song Q, Liu Z, Mia M, Maruda R, Krolczyk G (2019) Optimization of power consumption associated with surface roughness in ultrasonic assisted turning of Nimonic-90 using hybrid particle Swarm-Simplex method. Materials (Basel) 12(20). https://doi.org/10.3390/ma12203418

23. Ni C, Zhu L, Liu C, Yang Z (2018) Analytical modeling of tool-workpiece contact rate and experimental study in ultrasonic vibration-assisted milling of Ti-6Al-4V. Int J Mech Sci 142143:97-111. https://doi.org/10.1016/j.ijmecsci.2018.04.037

24. Rinck PM, Gueray A, Kleinwort R, Zaeh MF (2020) Experimental investigations on longitudinal-torsional vibration-assisted milling of Ti-6Al-4V. Int J Adv Manuf Technol 108(11-12):3607-3618. https://doi.org/10.1007/s00170-020-05392-w

25. Uhlmann E, Protz F, Stawiszynski B, Heidler S (2017) Ultrasonic assisted milling of reinforced plastics. Proc CIRP 66:164-168. https://doi.org/10.1016/j.procir.2017.03.278

26. Suárez A, Veiga F, de Lacalle LNL, Polvorosa R, Lutze S, Wretland A (2016) Effects of ultrasonics-assisted face milling on surface integrity and fatigue life of Ni-alloy 718. J Mater Eng Perform 25(11):5076-5086. https://doi.org/10.1007/s11665-016-2343-6

27. Slatineanu L, Wojciechowski S, Maruda RW, Krolczyk GM, Nagit G, Dodun O, Merticaru V, Coteata M, Ripanu MI, Mihalache AM, Boca M, Ibanescu R, Panait CE, Oancea G, Kyratsis P (2017) The application of response surface method to optimization of precision ball end milling. MATEC Web of Conferences 112 . https://doi.org/10.1051/matecconf/201711201004

28. Wang J, Zhang D, Wu B, Luo M (2017) Residual stresses analysis in ball end milling of nickel-based superalloy Inconel 718. Mater Res 20(6):1681-1689. https://doi.org/10.1590/1980-5373-mr-20 17-0561

29. Special Metals Corp (2005) INCONEL(R) alloy 725, Publication No. SMC-066

30. Shoemaker LE (2005) Alloys 625 and 725: trends in properties and applications. In: Loria E. (ed) Superalloys 718, 625, 706 and Derivatives 2005, TMS (The Minerals, Metals \& Materials Society), pp 409-418. https://doi.org/10.7449/2005/Superalloys_2005_ 409_418

31. Detrois M, Rozman KA, Jablonski PD, Hawk JA (2005) Compositional design and mechanical properties of inconel alloy 
725 variants. In: Springer International Publishing, Proceedings of the 9th International Symposium on Superalloy 718 \& Derivatives: Energy, Aerospace, and Industrial Applications, pp 421-437. https://doi.org/10.1007/978-3-319-89480-5_26

32. Yang P, Yao C, Xie S, Zhang D, Tang DX (2016) Effect of tool orientation on surface integrity during ball end milling of titanium alloy TC17. Proc CIRP 56:143-148. https://doi.org/10.1016/ j.procir.2016.10.044

33. Thakur A, Gangopadhyay S (2016) State-of-the-art in surface integrity in machining of nickel-based super alloys. Int J Mach Tools Manuf 100:25-54. https://doi.org/10.1016/j.ijmachtools.20 15.10.001
34. Fuchs C, Baier D, Semm T, Zaeh MF (2020) Determining the machining allowance for WAAM parts. Production Engineering. https://doi.org/10.1007/s11740-020-00982-9

35. Wagner M, Michels H, Hamm C, Appelt M, Roeser T, Weigold $M$ (2019) Influence of tool variables on wear when milling iron aluminide alloy Fe25Al1.5Ta [at.-\%]. Proc Manuf 40:1-7. https://doi.org/10.1016/j.promfg.2020.02.002

Publisher's note Springer Nature remains neutral with regard to jurisdictional claims in published maps and institutional affiliations. 